\title{
IONOSPHERIC ION COMPOSITION FROM SATELLITE MEASUREMENTS MADE DURING 1970-1980: ALTITUDE PROFILES
}

\author{
W.R. Hoegy,* J.M. Grebowsky* and L.H. Brace** \\ *NASA/Goddard Space Flight Center, Greenbelt, MD 20771, USA. \\ **Space Physics Research Laboratory, The University of Michigan, Ann Arbor, MI \\ 48109, USA.
}

\begin{abstract}
Ion mass spectrometers were carried by a number of satellites in the $1970 \mathrm{~s}$. The ion composition measurements from two of these missions, the Orbiting Geophysical Observatory- 6 and the Atmosphere Explorer-C, have been collected into an ion composition data base to evaluate several widely used empirical and theoretical models for the species $\mathrm{H}^{+}, \mathrm{He}^{+}, \mathrm{N}^{+}, \mathrm{O}^{+}, \mathrm{NO}^{+}, \mathrm{N}_{2}^{+}$, and $\mathrm{O}_{2}^{+}$. The data base covers all latitudes and local times, and the altitude range from $150 \mathrm{~km}$ to $1200 \mathrm{~km}$, but here we present altitude plots of the ion densities at noon and at dip latitudes of $20-40^{\circ} \mathrm{N}$. The satellite data are compared with an early ion density profile by Johnson, with the Koehnlein and IRI-90 empirical models, and with the Utah State University theoretical ionosphere model. These comparisons serve to verify some aspects of the models, but they also reveal some outstanding differences. The solar activity dependence of $\mathrm{H}^{+}$, $\mathrm{He}^{+}, \mathrm{N}^{+}$, and $\mathrm{O}^{+}$is demonstrated, although this has not been possible for the molecular ions because low altitude measurements have not been made near solar maximum.
\end{abstract}

\section{INTRODUCTION}

The importance of a knowledge of ion composition for understanding ionospheric plasma processes such as plasma outflow, the polar wind, ion chemistry, and a variety of plasma instabilities cannot be overstated. A series of satellites made in situ ion composition measurements between late the 1960s and the early 1980s. References to these satellites and the resulting data bases are given by Bilitza $/ 1,2 /$. Explorer 31 made ion composition measurements between 600 and $3600 \mathrm{~km}$ between November 1965 and January 1971. Additional ion mass spectrometer (IMS) measurements were made by Explorer 32 between May 1966 and March 1967, by OGO-6 between June 1969 and June 1971, by ISIS-2 between April 1971 and December 1972, by AE-C between December 1973 and December 1978, by S3-1 between November 1974 and May 1975, by TAIYO between February 1975 and May 1976, by AE-D between October 1975 and January 1976, by AE-E between November 1975 and June 1981, by S3-3 between July 1976 and March 1980, and by KYOKKO between February 1978 and November 1979. The only ion composition measurements during the 1980s were made between 800 and $900 \mathrm{~km}$ from IK1300 between August 1981 and December 1983 and from the AE-E at low latitudes and at altitudes in the vicinity of the F region peak.

Clearly, the 1970s provided a rich ion composition data base. These satellites covered a wide range of latitudes and altitudes, and the full range of local times were covered. Owing to the relatively short lifetimes of the satellites, however, the full range of solar cycle variations was not resolved, particularly for measurements in the lower $\mathrm{F}$ region which are only available from the deep diving $\mathrm{AE}$ satellites. $\mathrm{A}$ similar F region global data base is not available for the 1980 's. 
In this brief paper, altitude profiles of the ion composition measurements of the 7 species $\mathrm{H}^{+}, \mathrm{He}^{+}, \mathrm{N}^{+}$, $\mathrm{O}^{+}, \mathrm{N}_{2}^{+}, \mathrm{NO}^{+}$, and $\mathrm{O}_{2}^{+}$are constructed statistically from OGO-6 and AE-C ion measurements. AE-C was the first in a series of three Explorer satellites which were provided with propulsion to control perigee and apogee, thus making possible in situ measurements down to nearly $130 \mathrm{~km}$. See Hoegy and Grebowsky $/ 3$ / for further details on the AE-C orbit. These data are compared with the latest International Reference Ionosphere, IRI-90, (Bilitza, private communication), the empirical Koehnlein model /4, 5/, and the Utah State University theoretical model of Schunk $16 \%$. The data are also compared with the early altitude profile of Johnson $/ 7$, which was the first calibrated profile of ion density using satellite and rocket data.

\section{THE SATELLITES AND THE MODELS}

Before comparing the OGO-6 and AE-C data with the empirical and theoretical models, we provide further information on the satellites and the models. The OGO-6 and AE-C ion mass spectrometers were nearly identical instruments, and the data were not normalized to any other measurements, so comparisons are expected to be especially meaningful. However, the two missions were conducted at quite different parts of the solar cycle, so we have an opportunity to examine the variation of ion composition with solar activity, at least at altitudes near and above the $F 2$ peak.

The measurements used in the Johnson paper $7 /$ were made in early 1963 (rocket measurements from 90 $\mathrm{km}$ to $240 \mathrm{~km}$ ) and early 1964 (satellite measurement $400 \mathrm{~km}$ to $1200 \mathrm{~km}$ ). Thus the rocket and satellite data used by Johnson were not obtained simultaneously, and were not taken at the same local time or latitude. The rocket was launched at White Sands, New Mexico at 9:34 local time and $33^{\circ} \mathrm{N}$ latitude on February 15, 1963 while the the data from the Soviet satellite, Electron 2, covered the local time period $1400-1900 \mathrm{hrs}$ over latitudes $10^{\circ}-60^{\circ} \mathrm{N}$ latitude and at altitudes from $400 \mathrm{~km}$ to $1200 \mathrm{~km}$ during February 10-16, 1964. The ion composition measurements used by Johnson were converted to absolute ion densities by normalizing to electron densities obtained from simultaneous Doppler radio propagation and ionosonde measurements. This was a period of low solar activity, with the 3 month average $10.7 \mathrm{~cm}$ solar radio flux about $70 \mathrm{FU}$, similar to those present during most of the AE-C mission.

The OGO-6 data were obtained when the 3 month average $10.7 \mathrm{~cm}$ flux was about $140 \mathrm{FU}$. The OGO-6 data set covers the time period June 1969 to June 1971 in the altitude range $390 \mathrm{~km}$ to $1036 \mathrm{~km}$. For the present comparisons, only data in the local time range of 2 hrs about noon and in the dip latitude range $20-40^{\circ} \mathrm{N}$ were selected, and data from all seasons are included. The data were uniformly distributed in longitude (UT) and occurred in a 20 day interval centered on day 130 and in a 30 day interval centered on day 215 . These two intervals occur nearly symmetrically about summer solstice. The OGO-6 data were obtained from the NSSDC on IBM tapes which were converted from EBCDIC to ASCII format and stored on magnetic disk for data processing. The ASCII data were also written on magnetic tapes and returned to the NSSDC for archiving.

The lowest altitude AE-C data were obtained during the eccentric phase of that mission in 1974 when F10.7 was about $80 \mathrm{FU}$. In 1975 and 1976 , when $A E-C$ was in a circular orbit near the altitude of the $F$ peak (about $300 \mathrm{~km}$ ), the $10.7 \mathrm{~cm}$ flux was about 70 . During 1977 and 1978 the orbit was maintained at about $400 \mathrm{~km}$, and the $10.7 \mathrm{~cm}$ flux varied between 70 and 130, with an average of about $90 \mathrm{FU}$. Thus the lower altitude AE-C measurements represent the same solar minimum conditions as the early Johnson profiles. The circular orbit phase corresponded to more moderate solar activity. The AE-C data cover the time period from day 350 of 1973 to day 184 of 1978. The AE-C data used here covered the altitude range $150 \mathrm{~km}$ to $1200 \mathrm{~km}$ and were limited to local times of $2 \mathrm{hrs}$ about noon and the dip latitude range of $20-40^{\circ} \mathrm{N}$ for all seasons. These data occurred in 3 intervals about 20 days long, centered at days 50 , 130, and 255. Most of the data above $400 \mathrm{~km}$ occurred in the day 130 interval. The data are uniformly distributed in longitude. Thus at altitudes where the AE-C and OGO-6 data overlap, the two data sets have the same seasonal and longitude coverage. The AE-C data were obtained from the Unified Abstract file of $15 \mathrm{sec}$ averages which is also available from the NSSDC 
The IRI is a joint project of COSPAR and URSI which has evolved a series of empirical models of various parameters $/ 8 /$, see references in $/ 1 /$. The latest IRI model, IRI-90/9/ contains an improved ion composition model that is based on the Danilov-Yaichnikov model /10/ which was derived from high apogee rockets and the satellites Electron 2 and 4, and S3-1. The IRI-86 ion composition model was based on data from 42 rockets below $200 \mathrm{~km}$ and the AEROS satellite measurements at higher altitudes. The IRI model contains ion composition for only the 5 species $\mathrm{H}^{+}, \mathrm{He}^{+}, \mathrm{O}^{+}, \mathrm{NO}^{+}$, and $\mathrm{O}_{2}^{+}$from which the ion densities are obtained by multiplying the composition by the electron density. IRI-90 model values were derived for altitudes from $100 \mathrm{~km}$ to $1200 \mathrm{~km}$ at noon local time and for a dip latitude of $30^{\circ} \mathrm{N}$, for mid February and at a longitude of $106^{\circ} \mathrm{W}$ and low solar activity (70 FU) to match the conditions of the Johnson data. The longitude should not be important because the same dip latitudes were used as the data, however, the IRI model is dependent on longitude and in a small way on season (this will be discussed later).

The Koehnlein empirical model /4, 5/ is based on observation of AE-B, AE-C , AE-D, AE-E, ISIS-2, and OGO-6 satellites plus rocket data for quiet magnetic conditions $K_{p} \leq 3$. The model represents the 7 ion species $\mathrm{H}^{+}, \mathrm{He}^{+}, \mathrm{N}^{+}, \mathrm{O}^{+}, \mathrm{N}_{2}^{+}, \mathrm{NO}^{+}$, and $\mathrm{O}_{2}^{+}$and uses cubic splines to represent the vertical structure and employs harmonic functions for the horizontal dependence. The model is available only in the form of plots, therefore it is difficult to compare it under the same conditions as the other models and the OGO and $\mathrm{AE}$ data. We digitized the data from the Koehnlein plots of average density at low solar activity. The results should therefore compare well with the AE-C data plotted here.

The Utah State University (USU) theoretical model /6/ was used in a parameterized form provided by $R$. Daniell and D. Anderson (private communication) in which vector spherical harmonics were used to describe the model at high latitudes. Altitude profiles of $\mathrm{O}^{+}, \mathrm{NO}^{+}$, and $\mathrm{O}_{2}^{+}$were obtained between 100 $\mathrm{km}$ and $800 \mathrm{~km}$ for midday, summer conditions at low magnetic and solar activity, $B_{\mathrm{y}}$ positive, and 18 hrs UT. The model latitude selected was $51^{\circ} \Lambda$, since this is the lowest possible latitude covered by the model. This latitude is somewhat above the range of latitudes used for the comparison with other models and measurements, however, the comparison of general trends proved valuable.

\section{COMPARISONS OF THE AE-C AND OGO-6 DATA WITH THE MODELS.}

The altitude plots of the 7 selected species are shown in Figures 1-7. The points represent individual OGO-6 measurements, and the $15 \mathrm{sec}$ averaged values from the AE-C measurements. The horizontal striations in the AE-C data are an artifact of the denser measurement coverage at the different circular orbit altitudes that were maintained at various times in the mission. Averages of the AE-C data over a $50 \mathrm{~km}$ altitude interval are represented by filled circles, while the averages of the OGO-6 data over $50 \mathrm{~km}$ are represented by 5 -pointed stars. One sigma error bars are displayed. The solid lines represent the Johnson empirical model. Open circles represent the IRI-90 model; open triangles represent the Koehnlein model; and open squares represent the USU model.

\section{$\mathrm{H}^{+}$Density}

Figure 1 compares the $\mathrm{H}^{+}$densities from the satellites and the models. The AE-C data obtained during its eccentric phase extends down to about $230 \mathrm{~km}$ where the $\mathrm{H}^{+}$concentration fell below the spectrometer threshold. The error bars on the AE-C and OGO-6 average profiles indicate one standard deviation of the $\log$ of the densities within each $50 \mathrm{~km}$ interval. The OGO and AE data differ in important respects, with the AE-C values significantly higher between 500 and $900 \mathrm{~km}$. The AE-C $\mathrm{H}^{+}$density is a factor of 6.5 greater than the OGO- 6 density at $600 \mathrm{~km}$. This difference could be due to differences in solar activity, a different seasonal bias of the data sets, or a longitudinal bias of the data sets. As mentioned above, there is no longitudinal bias in the OGO-6 and AE-C coverage. The seasons are nearly the same where the data overlap in altitude, since most of the $O G O$ data above $600 \mathrm{~km}$ were taken midway between summer and fall, while the AE-C data were obtained midway between spring and summer. Therefore we conclude that 
the $\mathrm{H}^{+}$density differences in the OGO-6 and AE-C data are due to solar activity. This comparison shows that $\mathrm{H}^{+}$decreases with increasing solar activity.

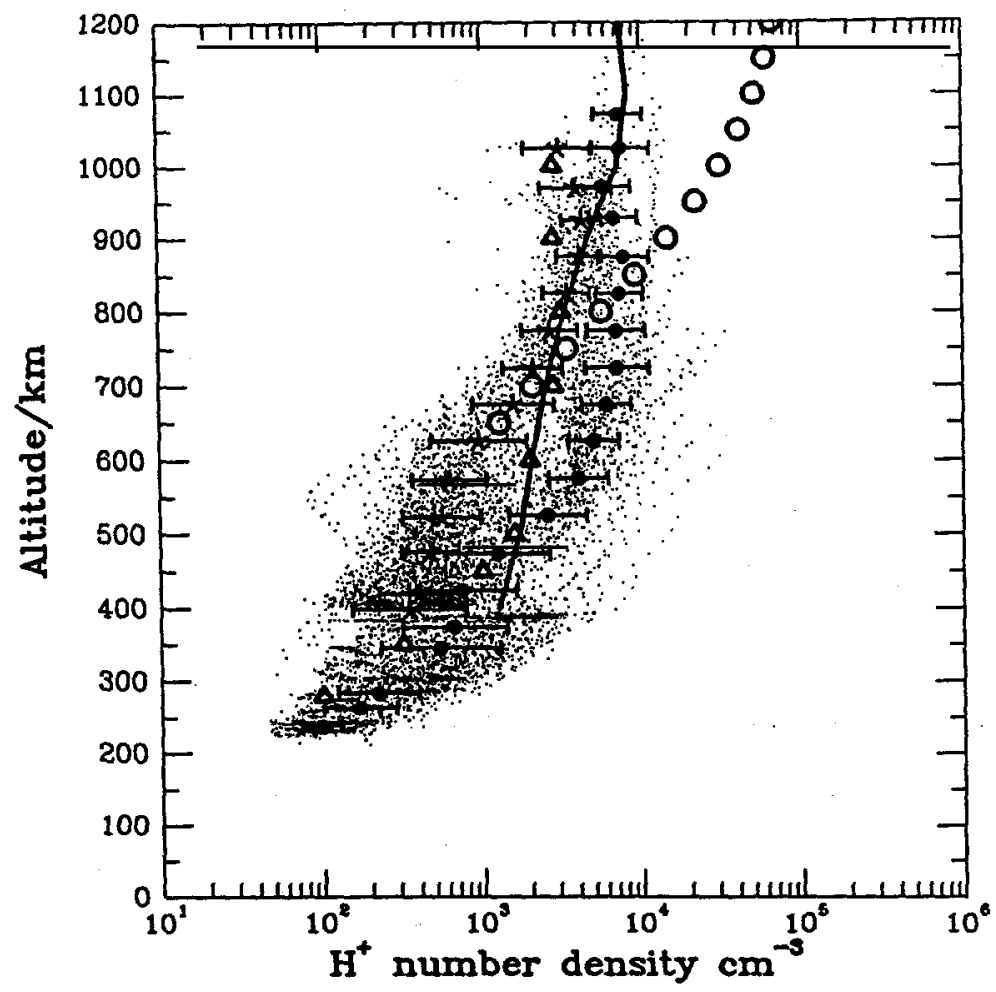

Fig. 1. Comparison of satellite data from AE-C and OGO-6 (points) for dip latitudes 20 to 40 and LST 10 to 14 with models for $\mathrm{H}^{+}$. Johnson model (solid line), AE-C average over $50 \mathrm{~km}$ (solid circle), OGO-5 average over $50 \mathrm{~km}$ ( 5 pointed star), IRI-90 model (open circle), and Koehnlein model (triangle). Altitude in $\mathrm{km}$ and number density in $\mathrm{cm}^{-3}$.

The Johnson profile falls generally between the AE-C and OGO-6 measurements, except below $500 \mathrm{~km}$ where it exceeds both of the satellite average profiles. The density gradient of the Johnson profile is rather flat compared with the data. The IRI-90 model $\mathrm{H}^{+}$profile is steeper than the satellite profiles, but it diverges above $800 \mathrm{~km}$ and is an order of magnitude greater than the AE-C values at $1200 \mathrm{~km}$. The IRI model extends only down to $650 \mathrm{~km}$ because ion composition less than $1 \%$ is neglected. The Koehnlein model agrees with the AE-C data below $500 \mathrm{~km}$ and tends to follow the OGO-6 data above $700 \mathrm{~km}$, although it should agree only with the low solar activity AE-C data.

A number of factors could contribute to the difference between the satellite and model profiles of $\mathrm{H}^{+}$. Longitude variation of the IRI model introduce a spread of about a factor of 4 in the density. The seasonal variation of IRI introduces about a $37 \%$ variation at $700 \mathrm{~km}$, with winter having the highest density and summer the lowest. The Koehnlein seasonal variation of $\mathrm{H}^{+}$is opposite to the IRI-90 variation. The width of the AE-C and OGO-6 bins $\left(20^{\circ}\right.$ in latitude, $4 \mathrm{hrs}$ in local time, all longitudes allowed, all magnetic activity allowed) contributes to the scatter in the satellite data.

\section{$\mathrm{He}^{+}$Density}

Figure 2 compares the $\mathrm{He}^{+}$densities from the satellites and the models. The AE-C and OGO-6 data and 
the Johnson profiles show nearly constant density between $600 \mathrm{~km}$ and $900 \mathrm{~km}$, with the satellite data about a factor of 3 lower. The AE-C values rise well above the OGO-6 measurements below $600 \mathrm{~km}$ where they agree better with the Johnson model. This behavior is consistent with solar activity biases in the data bases; at low altitudes $\mathrm{He}^{+}$decreases with increasing solar activity; at high altitudes it has the opposite behavior. The arguments used to rule out longitude and seasonal causes for differences in OGO6 and AE-C measurements of $\mathrm{H}^{+}$also apply to $\mathrm{He}^{+}$. The IRI-90 profile diverges radically from the data above $600 \mathrm{~km}$. Below $800 \mathrm{~km}$, the Koehnlein profile lies between the OGO-6 and AE-C averages. This behavior is not understood, since the Koehnlein profile is for low solar activity. Above $600 \mathrm{~km}$, the Koehnlein profile agrees well with the both the AE-C and OGO-6 data.

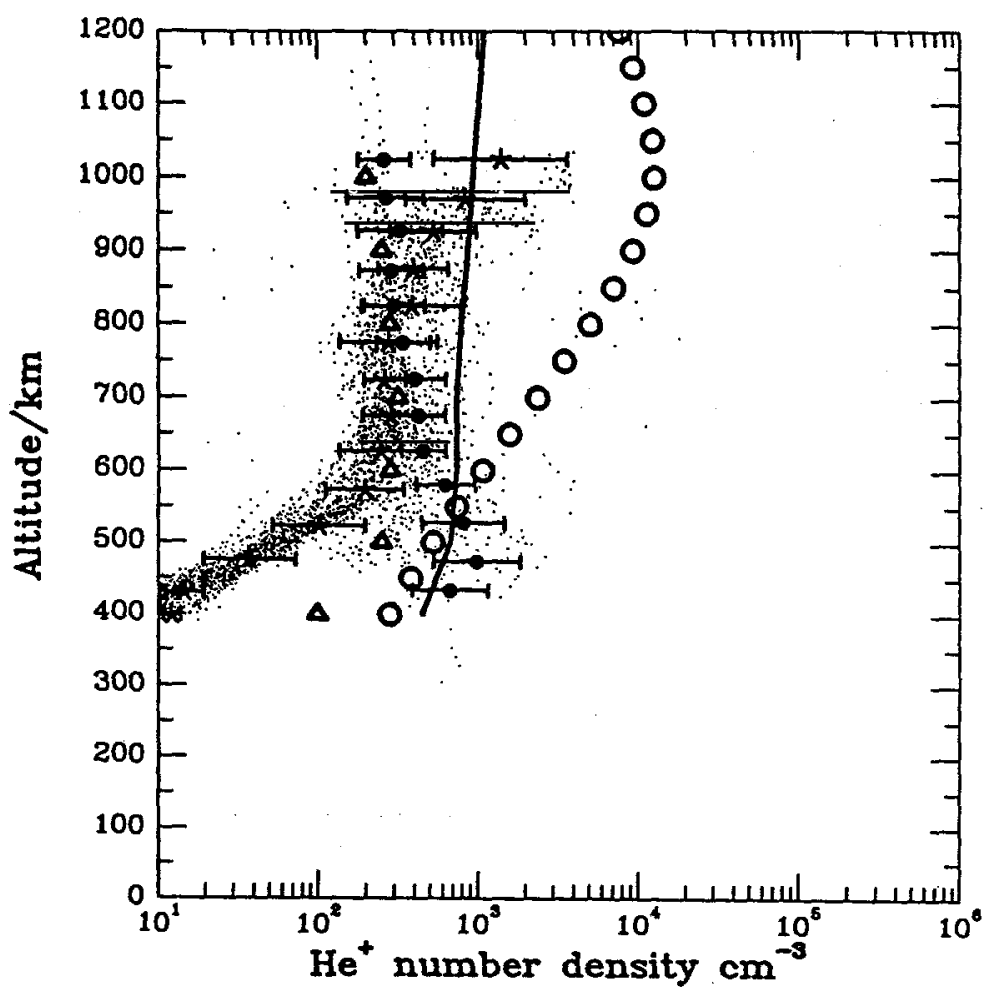

Fig. 2. Comparison of satellite data from AE-C and OGO-6 with Johnson, IRI, and Koehnlein models for $\mathrm{He}^{+}$. Same symbols as Fig. 1.

\section{$\underline{\mathbf{N}}^{+} \underline{\underline{\text { Density }}}$}

Figure 3 compares the $\mathrm{N}^{+}$densities from the satellites and the models. They agree well, except for the Koehnlein model. The Koehnlein model is consistently lower than the AE-C data and falls off faster than the data at the highest altitudes, although it has the same slope as the OGO-6 data above $400 \mathrm{~km}$. The differences between the OGO and AE measurements suggest a solar activity variation, with the $\mathrm{N}^{+}$ density increasing with increasing activity. This behavior is opposite that of the lighter ions in this altitude range. The Johnson profile agrees well with the OGO-6 and AE-C averages.

\section{$\underline{Q}^{+}$Density}

Figure 4 compares the $\mathrm{O}^{+}$densities from the satellites and the models. The OGO-6 and AE-C 


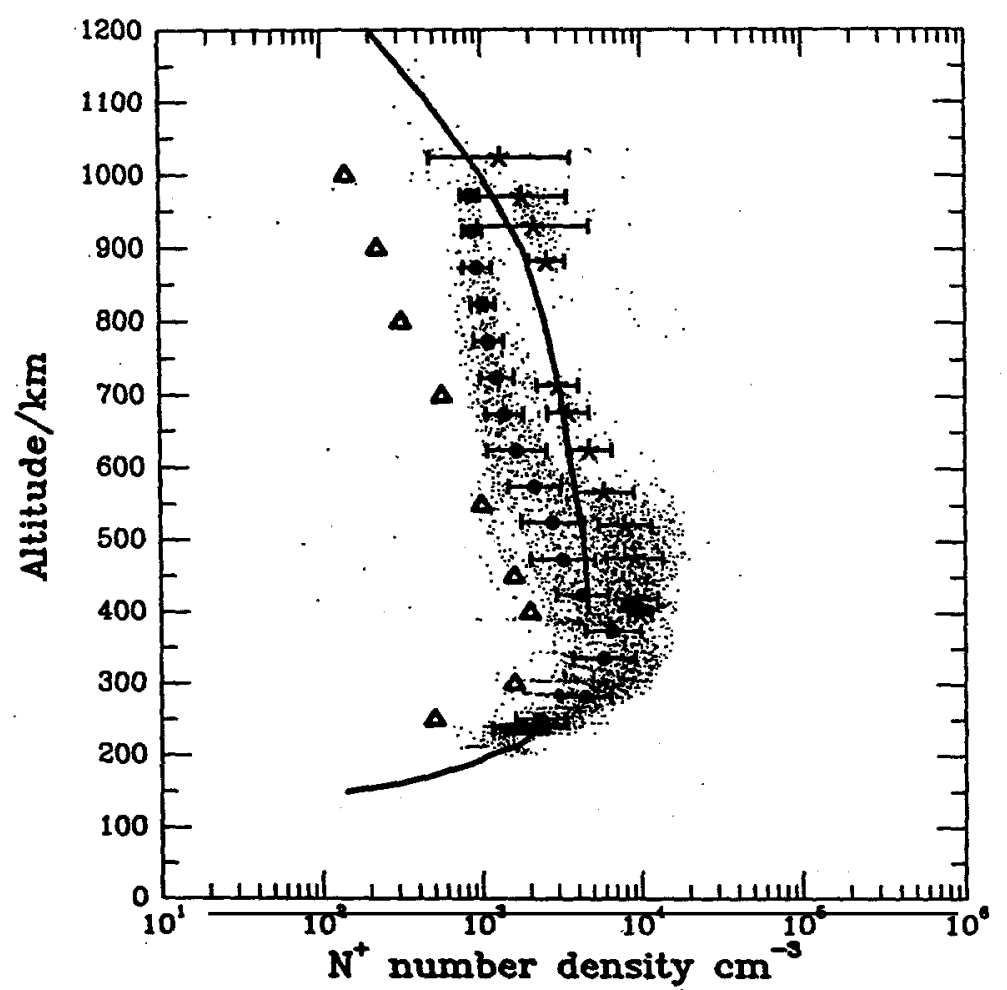

Fig. 3. Comparison of satellite data from AE-C and OGO-6 with Johnson and Koehnlein models for $\mathrm{N}^{+}$. Same symbols as Fig. 1.

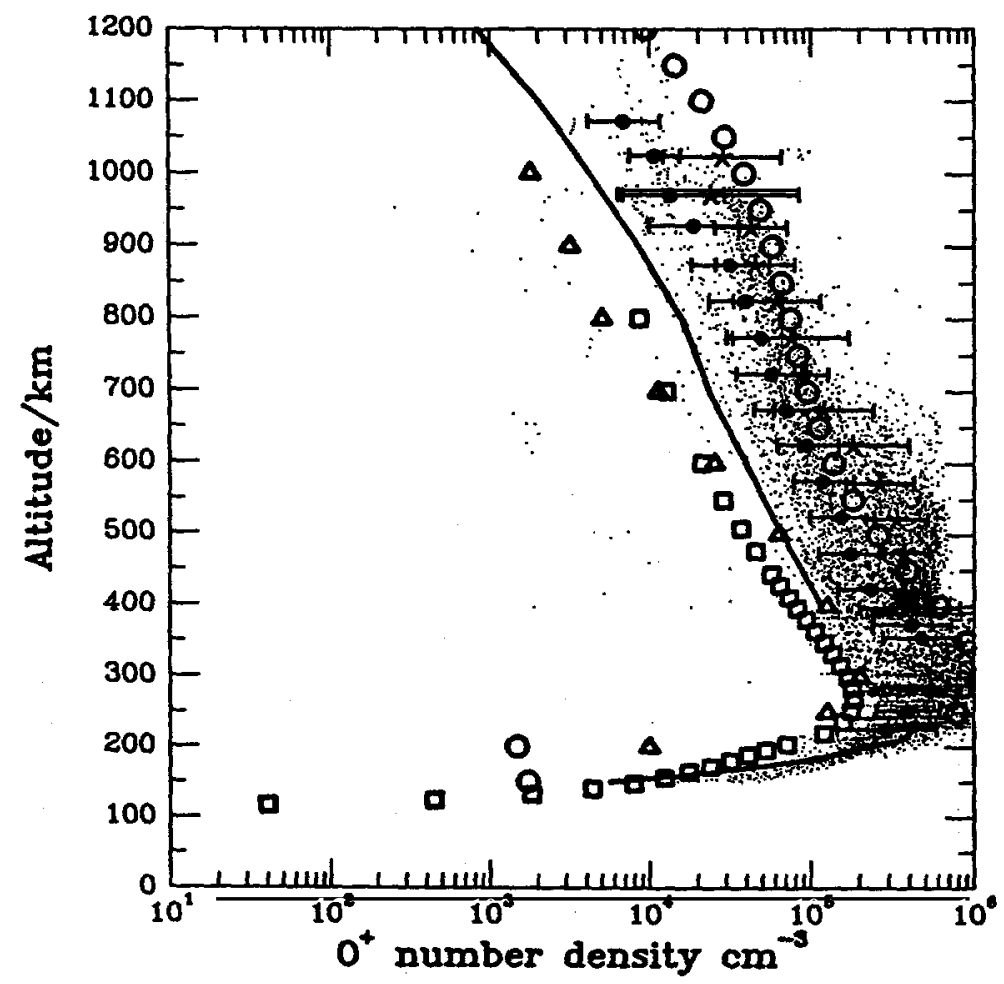

Fig. 4. Comparison of satellite data from AE-C and OGO-6 with Johnson, IRI, Koehnlein empirical models and USU theoretical model (square) for $\mathrm{O}^{+}$. Same symbols as Fig. 1. 
measurement reveal a small solar activity effect similar to that of $\mathbf{N}^{+}$, with the density increasing with increasing solar activity. The Johnson profile is consistently lower than the satellite data by about a factor of 4. The IRI-90 model agrees rather well with the OGO-6 data, and is higher than the AE-C data except at altitudes below the $F 2$ peak. The Koehnlein model falls about a factor of 4 below the AE-C data, but the profile has nearly the same shape. The shape of the USU model is also similar, but it falls below the data because the model corresponds to dip latitude of $55^{\circ}$ rather than $20-40$ degrees for the other profiles. If the behavior of the IRI model as a function of dip latitude is used to scale the USU model to $30^{\circ}$ dip latitude, then the USU model lies within the error bars of the AE-C data.

$\mathrm{N}_{2}+$ Density

Figure 5 compares the $\mathrm{N}_{2}^{+}$densities from the satellites and the models. The AE-C and OGO-6 data agree at $400 \mathrm{~km}$, but the error bars on the OGO-6 averages are so large that the increase in $\mathrm{N}_{2}{ }^{+}$above $400 \mathrm{~km}$ cannot be trusted. There may be some increase in $\mathrm{N}_{2}^{+}$, with increasing solar activity, but probably not enough to produce the observed difference in the averages of AE-C and OGO-6. The AE-C data appear to be consistent with the Johnson profile at $250 \mathrm{~km}$. The Koehnlein model also agrees with the AE-C data between $250 \mathrm{~km}$ and $400 \mathrm{~km}$, but exhibits a lower peak density than either the AE-C data or the Johnson profile.

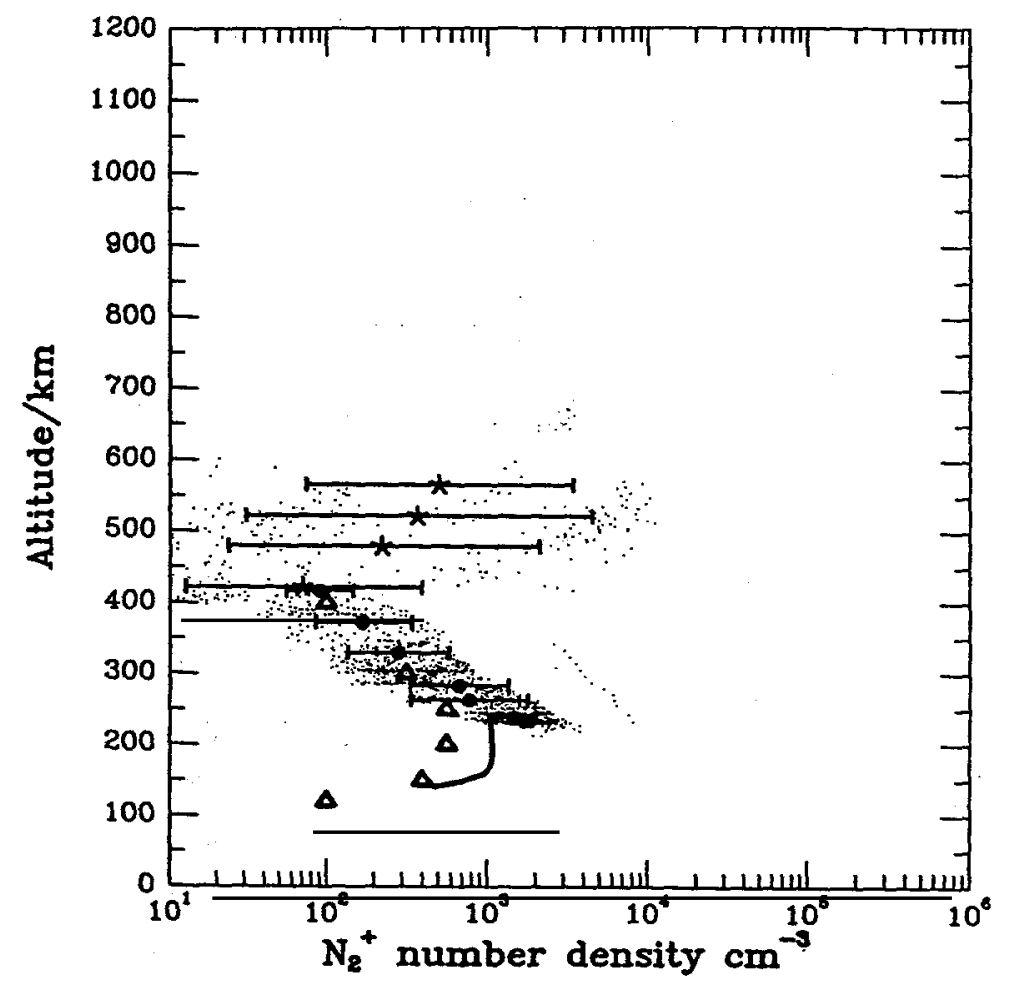

Fig. 5. Comparison of satellite data from AE-C and OGO-6 with Johnson and Koehnlein models for $\mathrm{N}_{2}^{+}$. Same symbols as Fig. 1. 


\section{NQ $^{+}$sity}

Figure 6 compares the $\mathrm{NO}^{+}$satellite measurements and the models. OGO-6 data are too sparse to place much credence in the differences evident above $400 \mathrm{~km}$. The Johnson profile is consistent with the AE-C data at $225 \mathrm{~km}$ where they overlap. The IRI-90 model agrees with the AE-C data above $250 \mathrm{~km}$. Below this altitude, IRI-90 exhibits a bite-out at about $190 \mathrm{~km}$ and a density increase at low altitude which is inconsistent with the Johnson and the USU profiles. The Koehnlein model exhibits a lower peak density at about $150 \mathrm{~km}$ than the other profiles, but is consistent with the AE-C data above $200 \mathrm{~km}$. The USU model agrees with the Johnson profile below the peak height and agrees with the AE-C data and IRI-90 above $200 \mathrm{~km}$. The IRI- 90 model indicates little latitude variation of the $\mathrm{NO}^{+}$density above $200 \mathrm{~km}$, therefore the USU model at $55^{\circ}$ dip latitude should agree with the data and IRI model at $30^{\circ}$ dip latitude, which it does. The two layer structure of the IRI-90 model at $30^{\circ}$ dip latitude disappears at $55^{\circ}$ dip latitude.

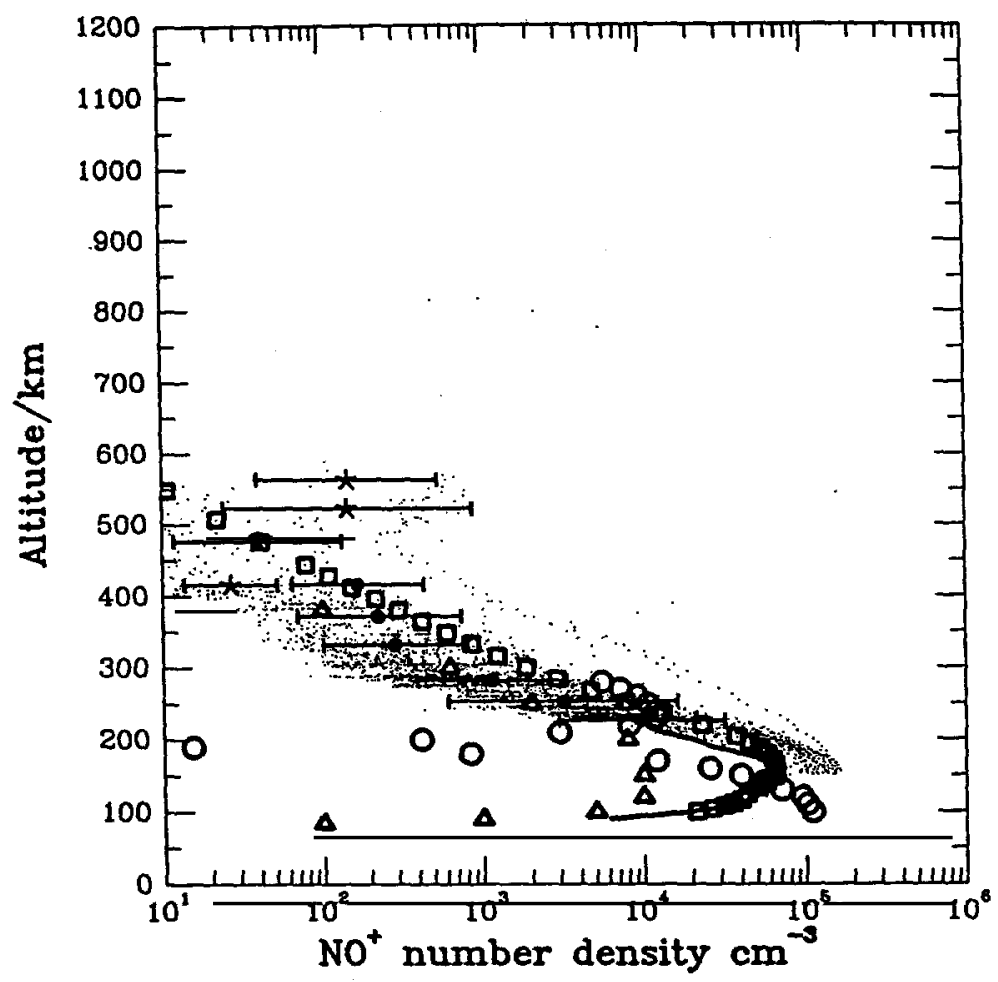

Fig. 6. Comparison of satellite data from AE-C and OGO-6 with models for $\mathrm{NO}^{+}$. Same symbols as Fig. 4,

\section{$\mathrm{Q}_{2}^{+}$}

Figure 7 compares the $\mathrm{O}_{2}{ }^{+}$densities from the satellites and the models. The AE-C and OGO-6 densities agree very well up to about $400 \mathrm{~km}$, where a few outlier points cause the AE-C average to diverge from the general trend. The Johnson profile matches the AE-C trend where they overlap between 150 and 210 $\mathrm{km}$. The IRI-90 profile is slightly higher than AE-C at altitudes above $250 \mathrm{~km}$, and is lower than the Johnson profile at lower altitudes. The Koehnlein profile agrees with the AE-C data above $250 \mathrm{~km}$ and 
exhibits a two layer structure at lower altitudes as does the IRI-90 profile. The USU profile is consistent with the AE-C data above the $F$ peak.

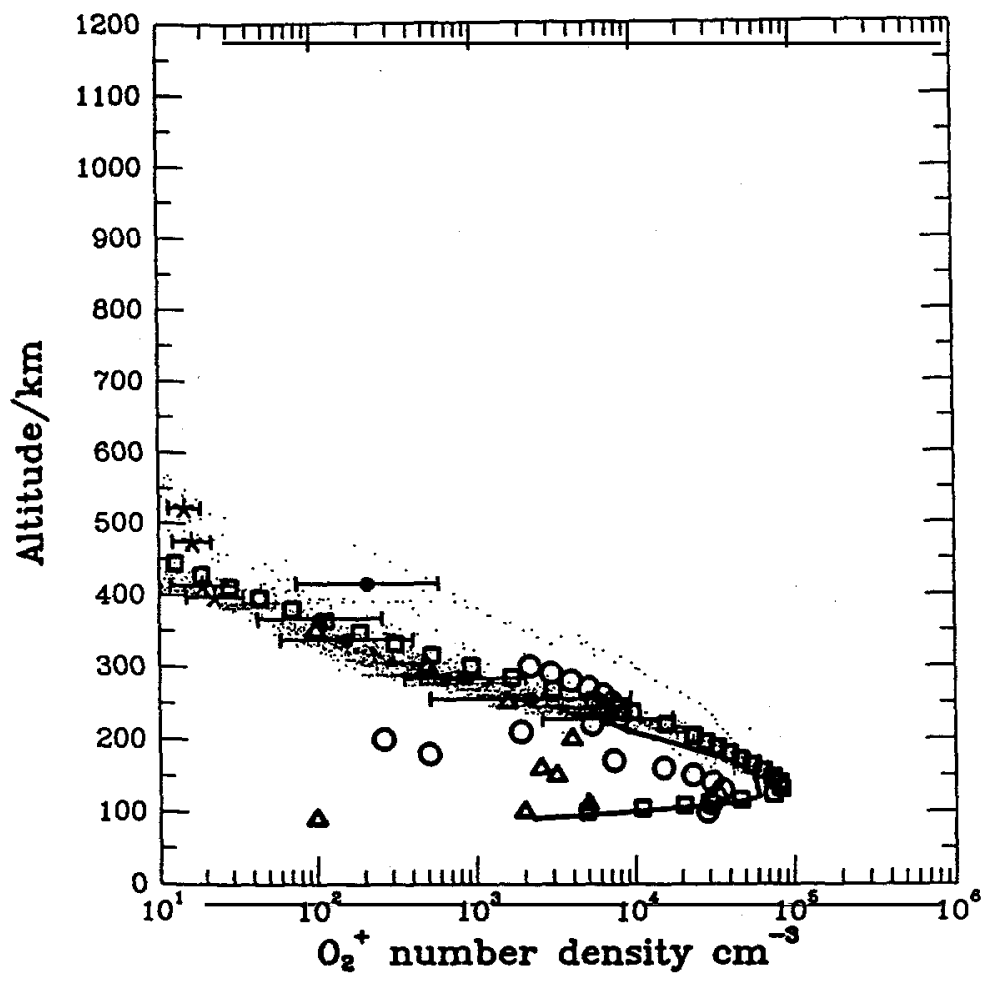

Fig. 7. Comparison of satellite data from AE-C and OGO-6 with models for $\mathrm{O}_{2}^{+}$. Same symbols as Fig. 4.

\section{CONCLUSIONS}

The 7 ions $\mathrm{H}^{+}, \mathrm{He}^{+}, \mathrm{N}^{+}, \mathrm{O}^{+}, \mathrm{N}_{2}^{+}, \mathrm{NO}^{+}$, and $\mathrm{O}_{2}^{+}$measured by AE-C during solar minimum and by OGO-6 during a rather weak solar maximum have been displayed as altitude plots and compared with early altitude profiles of Johnson, with the IRI-90 and Koehnlein empirical models, and with the USU theoretical model. The satellite data indicate that the Johnson profiles are reasonable representations of the ion density, differing at the most by about a factor of 3 . The Johnson profiles are systematically higher than the $\mathrm{AE}$ and $\mathrm{OGO}$ satellite measurements for $\mathrm{He}^{+}$and $\mathrm{N}^{+}$and are lower for $\mathrm{O}^{+}$. The Koehnlein model at low solar activity should agree with the AE-C data, however, it sometimes agrees better with the OGO measurements, and it is systematically lower for $\mathrm{N}^{+}$and $\mathrm{O}^{+}$. If the Koehnlein model were available in computer form, additional comparisons with the AE-C and OGO-6 data could be made more readily. The IRI-90 model does not agree well with the satellite data for $\mathrm{H}^{+}$and $\mathrm{He}^{+}$, and its values for $\mathrm{O}^{+}$are about a factor of 2 higher than the AE-C averages. For $\mathrm{NO}^{+}$and $\mathrm{O}_{2}^{+}$above $250 \mathrm{~km}$, the IRI-90 is higher than the satellite data. The USU model, when corrected for the latitude differences, agrees within a factor of 2 with the AE-C data. A better comparison with the USU model will be possible in the future when that model is available at lower latitudes.

We determined the variation of ion composition with solar activity. $\mathrm{H}^{+}$and $\mathrm{He}^{+}$decrease with increasing with solar activity, whereas $\mathrm{N}^{+}, \mathrm{O}^{+}$increase. Since the OGO data exist only above $390 \mathrm{~km}$, the 
variation of the molecular ions, $\mathrm{N}_{2}^{+}, \mathrm{NO}^{+}, \mathrm{O}_{2}^{+}$, cannot be determined from this data base. More low altitude data are needed at higher solar activity levels.

These comparisons of the AE-C and OGO-6 ion composition measurements with the most widely used empirical and theoretical models have revealed a number of shortcomings in our understanding of some of the fundamental aspects of ionosphere behavior, particularly the variations in ion composition with solar activity. They demonstrate the need for further verification and upgrading of the models using existing spacecraft data, and the need for additional in situ measurements from deep diving satellites, particularly near solar maximum.

\section{REFERENCES}

1. Bilitza, D. The Worldwide Ionospheric Data Base, NSSDC/WDC-A-R\&S 89-03, Goddard Space Flight Center, Greenbelt, Maryland (April 1989).

2. Bilitza, D., Empirical modeling of ion composition in the middle and topside ionosphere, Ady. Space Res. , in print (1990).

3. Hoegy, W. R. and J. M. Grebowsky, Response of polar cap F-region to changing magnetic and solar conditions, L Geophys. Res, in print (1990).

4. Koehnlein, W., A model of the terrestrial ionosphere in the altitude interval $50-4000 \mathrm{~km}$. I. atomic ions ( $\mathrm{H}+, \mathrm{He}+, \mathrm{N}+, \mathrm{O}+)$., Earth. Moon and Planets $45 \# 1,53$ (1989).

5. Koehnlein, W., A model of the terrestrial ionoslphere in the altitude interval $50-4000 \mathrm{~km}$. II. molecular ions (N2+,NO+, and $\mathrm{O2+}$ ) and electron density., Earth Moon and Planets 47 \#2, 109 (1989).

6. Schunk, R. W., Mathematical structure of transport equations for multispecies flows, Rev. Geophys. 15,427 (1977).

7. Johnson, C. Y., Ionospheric composition and density from 90 to 1200 kilometers at solar minimum, J. Geophys. Res. 71 \#1, 330 (1966).

8. Rawer, K., S. Ramakrishnan and D. Bilitza. International Reference Ionosphere, URSI, Brussels, Belgium (1978).

9. Bilitza, D., International Reference Ionosphere, NSSDCAWDC-A-R\&S 90-22, Goddard Space Flight Center, Greenbelt, Maryland (November 1990).

10. Danilov, A. D. and A. P. Yaichnikov, A new model of the ion composition at 75 to $1000 \mathrm{~km}$ for IRI, Adv. Space Res, 5 \#7, 75 (1985). 